\title{
Annexin A2 Regulates TRPA1-Dependent Nociception
}

\author{
OLuca Avenali, ${ }^{1}$ Pratibha Narayanan, ${ }^{1}$ Tom Rouwette, ${ }^{1}$ Ilaria Cervellini, ${ }^{2}$ Michael Sereda, ${ }^{2}$ David Gomez-Varela, ${ }^{1}$ \\ and Manuela Schmidt ${ }^{1}$ \\ ${ }^{1}$ Somatosensory Signalling Group and 2Department of Neurogenetics, Max Planck Institute of Experimental Medicine, D-37075 Goettingen, Germany
}

The transient receptor potential A1 (TRPA1) channel is essential for vertebrate pain. Even though TRPA1 activation by ligands has been studied extensively, the molecular machinery regulating TRPA1 is only poorly understood. Using an unbiased proteomics-based approach we uncovered the physical association of Annexin A2 (AnxA2) with native TRPA1 in mouse sensory neurons. AnxA2 is enriched in a subpopulation of sensory neurons and coexpressed with TRPA1. Furthermore, we observe an increase of TRPA1 membrane levels in cultured sensory neurons from AnxA2-deficient mice. This is reflected by our calcium imaging experiments revealing higher responsiveness upon TRPA1 activation in AnxA2-deficient neurons. In vivo these findings are associated with enhanced nocifensive behaviors specifically in TRPA1-dependent paradigms of acute and inflammatory pain, while heat and mechanical sensitivity as well as TRPV1mediated pain are preserved in AnxA2-deficient mice. Our results support a model whereby AnxA2 limits the availability of TRPA1 channels to regulate nociceptive signaling in vertebrates.

Key words: membrane abundance; nociception; protein-protein interaction; TRPA1 channels

\section{Introduction}

The ability to sense harmful stimuli is of central importance for survival. In vertebrates, somatosensory neurons are equipped with primary signal detectors among which the transient receptor potential ion channel A1 (TRPA1) plays an essential role as a polymodal detector for potentially harmful chemicals and tissue damage (Bandell et al., 2004; Jordt et al., 2004; Bautista et al., 2006; Meseguer et al., 2014).

Beyond direct activation by its ligands, TRPA1 modulation is implicated in physiological phenomena of hypersensitivity, which are thought to contribute to conditions of chronic pain (Hucho and Levine, 2007; Patapoutian et al., 2009). Many proinflammatory signaling pathways affect TRPA1 activity. Proteinase-activated receptor 2 and bradykinin sensitize TRPA1 via phosphorylation (Chen et al., 2011) and via activation of PLC, which in turn releases phosphatidylinositol-4,5-bisphosphatemediated TRPA1 inhibition (Dai et al., 2007; S. Wang et al., 2008). The latter also seems at play during heterologous (mediated by the TRPV1 agonist capsaicin) desensitization of TRPA1

Received May 3, 2014; revised Sept. 3, 2014; accepted Sept. 10, 2014.

Author contributions: D.G.-V. and M. Schmidt designed research; L.A., P.N., T.R., I.C., D.G.-V., and M. Schmidt performed research; M. Sereda contributed unpublished reagents/analytic tools; L.A., D.G.-V., and M. Schmidt analyzed data; D.G.-V. and M. Schmidt wrote the paper.

This work was supported by the Emmy Noether-Program of the Deutsche Forschungsgemeinschaft (SCHM 2533/ 2-1). We thank Katherine A. Hajjar (Weill Cornell Medical College) for kindly providing AnxA2 ${ }^{-1-}$ mice. Further, we thank Sergej Zeiter (MPI for Experimental Medicine, Goettingen, Germany) for excellent technical assistance. Our special thanks go to Eric Peters (GNF, La Jolla, CA) for performing mass spectrometry and Donna Eckert (GNF, La Jolla, CA) for helping with sample preparation. We are very grateful to Walter Stühmer and Luis Pardo (MPI for Experimental Medicine, Goettingen, Germany) for generously providing the electrophysiology equipment. We are especially grateful to Ardem Patapoutian (TSRI, La Jolla, CA) who supported initial work on this project.

The authors declare no competing financial interests.

Correspondence should be addressed to either David Gomez-Varela or Manuela Schmidt, Max-Planck Institute of Experimental Medicine, Somatosensory Signalling Group, D-37075 Goettingen, Germany, E-mail: gomezvarela@em.mpg.de or mschmidt@em.mpg.de.

DOI:10.1523/JNEUROSCI.1801-14.2014

Copyright $\odot 2014$ the authors $\quad 0270-6474 / 14 / 3414506-11 \$ 15.00 / 0$
(Ruparel et al., 2008). Very recently, activation of TRPA1 has also been reported by the extracellular miRNA let-7b via functional coupling to toll-like receptor-7 (Park et al., 2014).

In addition, the abundance of TRPA1 channels at the plasma membrane has been identified as a crucial contributor to TRPA1 signaling (Schmidt et al., 2009). While detailed mechanistic insights into the regulation of TRPA1 surface levels are sparse, it has been shown to influence various aspects of TRPA1 function. For example, TRPV1 channels, which are coexpressed with TRPA1 in sensory neurons, counteract pharmacological desensitization of TRPA1 by preventing TRPA1 internalization (Akopian et al., 2007). Furthermore, the splice isoform TRPAlb increases TRPA 1 surface levels along with TRPA1 activation (Zhou et al., 2013).

These studies highlight the impact the regulation of ion channel membrane levels can exert on neuronal activity. For that reason the abundance of ion channels at the plasma membrane has to be tightly controlled - a process that is often accomplished by protein-protein interactions. For example, the surface delivery and retrieval of AMPA-type glutamate receptors in the CNS is fine-tuned by associated proteins, which consequently affects synaptic plasticity (Anggono and Huganir, 2012; Schwenk et al., 2012). In analogy, chronic inflammatory pain involves orchestrated protein interactions to control NMDA-type glutamate receptors (Tappe et al., 2006; Liu et al., 2008). Considering the crucial role of TRPA1 in pain signaling, we are in urgent need to improve our knowledge about the molecular mechanisms and protein interactions controlling TRPA1 surface abundance in sensory neurons.

Here we describe an unbiased proteomics approach by which we identified Annexin A2 (AnxA2) as a binding partner of endogenous TRPA1 channels in mouse sensory neurons. Using calcium imaging, live labeling, and electrophysiology we provide evidence that AnxA2 limits the abundance of TRPA1 channels at the plasma membrane of sensory neurons. Our in vitro observations are 
reflected by enhanced TRPA1-dependent pain in AnxA2-deficient mice. These results demonstrate a role for AnxA2 as an endogenous regulator of TRPA1 and shed light on a mechanism capable of controlling TRPA1-mediated nociception in vertebrates.

\section{Materials and Methods}

Reagents. Mustard oil (AITC), capsaicin, complete Freund's adjuvant (CFA), and DMSO were purchased from Sigma-Aldrich. Growth factors were purchased from R\&D Systems, and cell culture reagents from Life Technologies (Gibco) except poly-D-lysine (Millipore) and papain (Worthington). All reagents for PAGE were purchased from Life Technologies (NuPAGE).

Protein identification by MS and database search. Proteins were identified by MS using an LTQ-Orbitrap mass spectrometer (Thermo Fisher Scientific) essentially as described previously (Gómez-Varela et al., 2012) except that tandem MS data were used to search a mouse-specific database with an appended reverse sequence copy (EBI-IPI database version 3.32). Proteins were only considered if they were identified by two or more peptides in both independent TRPA1 affinity purifications from trigeminal ganglia (TG) lysates and were absent in the two independent replicates of the control experiment (IgG). Scaffold (version Scaffold_4.0.5; Proteome Software) was used to validate MS/MS-based peptide and protein identifications. Peptide identifications were accepted if they could be established at $>95 \%$ probability by the Peptide Prophet algorithm (Keller et al., 2002). Protein identifications were accepted if they could be established at $>95 \%$ probability and contained at least two identified peptides.

Cloning of the AnxA2 N-term deletion construct. The cDNA of mouse AnxA2 was used as a template for a PCR designed to delete the first 15 aa of the $\mathrm{N}$ terminus of AnxA2 using the following primers: GATCATTCTACACCCCCAAG and TCAGTCATCCCCACCACACAG. Primers were designed with BamHI and EcoRV restriction sites to insert the PCR product into pcDNA3-PV-IRES-EGFP (a kind gift from Nils Brose, MPIEM, Goettingen, Germany). Obtained clones were verified by sequencing.

HEK cell culture and transfection. HEK293T cells were maintained at $37^{\circ} \mathrm{C}, 5 \% \mathrm{CO}_{2}$ in DMEM (+ GlutaMAX) containing $10 \%$ FBS and antibiotic/antimycotic. Upon transient transfection using FuGENE, HD cells were plated on coverslips (for calcium imaging and electrophysiology) or MatTek dishes (for live labeling) coated with poly-D-lysine $(1 \mathrm{mg} / \mathrm{ml})$ and laminin $(20 \mu \mathrm{g} / \mathrm{ml})$. Twenty-four hours after plating cells were used for biochemistry, electrophysiology, or calcium imaging.

Protein affinity purification from tissue lysates and coimmunoprecipitation from cell lysates. HEK293T cells were transfected with cDNA encoding for murine TRPA1-myc, AnxA2, $\triangle$ AnxA2, p11, TRPV1, or empty plasmid (Mock) and were plated in $10 \mathrm{~cm}$ tissue culture dishes. After $24 \mathrm{~h}$ cells were collected in PBS, centrifuged, and the cell pellet was resuspended in lysis buffer ( $150 \mathrm{~mm} \mathrm{NaCl}, 50 \mathrm{~mm}$ Tris-HCl, pH 7.5, $0.5 \mathrm{~mm}$ EDTA, 10\% glycerol, 1\% NP-40, 0.5\% deoxycholate, and protease inhibitors). TG were freshly extracted from male wild-type mice (6-12 weeks old), and homogenized in lysis buffer using a glass dounce homogenizer. After centrifugation (10,000 rpm, $10 \mathrm{~min}$ ) the resulting supernatant from TG lysates was incubated at $4^{\circ} \mathrm{C}$ for $5 \mathrm{~h}$ with $20 \mu \mathrm{g}$ of TRPA 1 antibodies (rabbit, E1 or E3; Schmidt et al., 2009) or $20 \mu \mathrm{g}$ of rabbit IgG coupled to magnetic beads (Protein G Dynabeads; Life Technologies).The supernatant from HEK293T cell lysates was incubated at $4^{\circ} \mathrm{C}$ overnight either with $20 \mu \mathrm{g}$ of myc antibody (9E11 mouse; Santa Cruz Biotechnology), 10 $\mu \mathrm{g}$ of TRPA1 antibody (Schmidt et al., 2009), or with $20 \mu \mathrm{g}$ of TRPV1 antibody (goat; Santa Cruz Biotechnology) coupled to magnetic beads. After five washes in lysis buffer, beads were eluted by incubation for 10 min at $70^{\circ} \mathrm{C}$ in $40 \mu \mathrm{l}$ of elution buffer containing: the following $1 \times$ lithium dodecyl sulfate sample buffer (Life Technologies) and $1 \times \mathrm{Nu}-$ PAGE sample-reducing agent (Life Technologies). The resulting mixtures were resolved by $1 \mathrm{D}$ NuPAGE. In case of tissue samples each resolved lane was cut into 16 equal gel slices, which were analyzed separately by mass spectrometry. In the case of cell lysates protein gels were used for Western blotting followed by immunodetection.

Western blotting. Protein gels of cell lysates were blotted on nitrocellulose or PVDF membranes using the iBlot System (Life Technologies).
Detection of immunolabeled protein was performed using infrared imaging (Odyssey; Li-Cor). Western blots were incubated overnight with primary antibodies to myc (mouse; 1:100; Santa Cruz Biotechnology 9E11), Annexin A2 (rabbit; 1:100; Abcam), p11 (goat; 1:40; R\&D Systems), and TRPV1 (goat; 1:100; Santa Cruz Biotechnology). Western blots were independently repeated three times. Only for presentation purposes were size, brightness, and contrast levels of paired blots (i.e., experiments done in parallel and probed with the same antibody) adjusted using Photoshop CS6 (Adobe).

Electrophysiology. Whole-cell voltage-clamp recordings were performed in transfected HEK293T cells (for transfection conditions see Fig. 2) or transfected DRG cultures at room temperature with standard patch pipettes (3-5 M $\Omega$ resistance) made of borosilicate glass capillaries. Current signals were recorded with an EPC-9 patch-clamp amplifier (HEKA). Stimulus delivery and data acquisition were performed using Pulse software (HEKA). Current-voltage $(I / V)$ curves were performed using voltage steps of $400 \mathrm{~ms}$ duration ranging from -100 to $+175 \mathrm{mV}$ followed by an invariant pulse at $-75 \mathrm{mV}(400 \mathrm{~ms})$. The holding potential was set to $0 \mathrm{mV}$. To repress inactivation of voltage-dependent currents (Macpherson et al., 2007; Meseguer et al., 2014), these recording were made in $\mathrm{Ca}^{2+}$-free solutions [intracellular solution (in mM): 140 $\mathrm{NaCl}, 5 \mathrm{CsCl}, 10 \mathrm{EGTA}$, and 10 HEPES, pH 7.4, adjusted with $\mathrm{NaOH}$; bath solution (in mM): $140 \mathrm{NaCl}, 3 \mathrm{KCl}, 1.3 \mathrm{MgCl}_{2}, 10$ HEPES, 1 EGTA, and 10 glucose]. Mustard oil (MO)-dependent currents in both TRPA1transfected HEK293T cells and TRPA1-transfected DRG neurons were recorded using an extracellular $\mathrm{Ca}^{2+}$-containing solution to preserve and study agonist desensitization properties [Macpherson et al., 2007; intracellular solution (in mM): $135 \mathrm{KCl}, 2 \mathrm{MgCl}_{2}, 2 \mathrm{MgATP}, 5 \mathrm{EGTA}$, and 10 HEPES, pH 7.4; bath solution (in mM): $127 \mathrm{NaCl}, 3 \mathrm{KCl}, 1 \mathrm{MgCl}_{2}, 10$ HEPES, $2.5 \mathrm{CaCl}_{2}$, and 10 glucose, $\mathrm{pH}$ 7.3]. The effect of $\mathrm{MO}$ on $\mathrm{I} / \mathrm{V}$ curves was studied using voltage ramps of $500 \mathrm{~ms}$ ranging from -100 to $+100 \mathrm{mV}$, applied every $5 \mathrm{~s}$. The holding potential was set at $-70 \mathrm{mV}$. Data analysis and representation were done using FitMaster (HEKA) and Igor Pro (WaveMetrics), respectively.

Ratiometric calcium imaging. Ratiometric calcium imaging was performed essentially as described previously (Coste et al., 2010) using an inverted microscope (Zeiss Axio Observer Z1). Experiments were conducted $24-48 \mathrm{~h}$ after plating.

For experiments assessing the pharmacological desensitization of TRPA1, the following stimulus protocol was applied: (1) application of $50 \mu \mathrm{M}$ MO for $2 \mathrm{~min}$ followed by a second $2 \mathrm{~min}$ application of $50 \mu \mathrm{M}$ MO 2 min later (homologous desensitization) and (2) application of $0.5 \mu \mathrm{M}$ Capsaicin (Cap) for $1.5 \mathrm{~min}$ followed by $2 \mathrm{~min}$ application of $50 \mu \mathrm{M}$ MO 5 min later (heterologous desensitization; the longer interval between stimuli was necessary for recovery of intracellular calcium levels after Cap application).

Threshold for activation was set at $20 \%$ above the averaged baseline from five time points immediately before addition of each stimulus. The intracellular calcium concentration is expressed as the $340 / 380$ ratio. All experimental groups to be compared were processed in parallel using the same culture preparation. At least two coverslips from three independent culture preparations were analyzed per experimental paradigm.

Immunohistochemistry. Mice (ages 6-12 weeks) and rats (ages 6-8 weeks) were killed with $\mathrm{CO}_{2}$. DRG were carefully dissected, collected in $4 \%$ PFA/PBS, and fixed overnight at $4^{\circ} \mathrm{C}$. After cryoprotection in $30 \%$ sucrose/PBS overnight tissues were frozen in optimal cutting temperature medium, sectioned as step serial sections with a cryostat at $10 \mu \mathrm{m}$ width, mounted on SuperFrost Plus slides, and stored at $-80^{\circ} \mathrm{C}$. Frozen slides were thawed at room temperature for $30 \mathrm{~min}$, washed three times in PBS with $0.4 \%$ Triton X-100 (PBT), blocked for 30 min in PBT containing $5 \%$ goat or donkey serum, and incubated overnight at $4^{\circ} \mathrm{C}$ with primary antibodies diluted in blocking solution.

The following antibodies were used: 1:50 rabbit anti-TRPA1, custommade E1 or E3 (Schmidt et al., 2009), or 1:100 rabbit anti-TRPA1 (Aviva Systems Biology); 1:100 rabbit anti-TRPV1 (Alomone Labs); 1:100 rabbit anti-Annexin A2 (Abcam); 1:40 goat anti-p11 (R\&D Systems); 1:100 chicken anti-Peripherin (Abcam); and 1:200 rabbit anti-NF200 (SigmaAldrich). The antibody used on rat sections is 1:50 mouse anti-Annexin A2 (BD Biosciences). 
The sections were then washed five times in PBT and incubated for $2 \mathrm{~h}$ at room temperature with secondary antibodies conjugated to Alexa Fluor 488 and Alexa Fluor 546 (Life Technologies) diluted 1:250 in blocking solution. Sections were then washed five times in PBT and mounted in SlowFade Gold reagent (Life Technologies).

Image acquisition and analysis of immunohistochemistry. Digital images of stained cryosections were obtained by fluorescence microscopy (either using a Zeiss Axio Observer Z1 epifluorescence microscope or the Leica SP5 confocal laser scanning microscope). Images for all experimental groups were taken using identical acquisition parameters. All groups to be compared were processed simultaneously using the same culture or tissue preparation.

Raw images were analyzed by using NIH ImageJ essentially as described previously (Schmidt et al., 2009). In cryosections neurons were considered TRPA1-positive if the mean fluorescence intensity (measured in arbitrary units, AU) was higher than the mean background fluorescence plus four times the SD measured from at least 10 random unstained cells. For TRPA1 labeling the analysis was performed using three different TRPA1 antibodies (as described above), which gave similar results. Neurons were considered positive for the other labels if the mean fluorescence intensity (measured in AU) was higher than the mean background fluorescence plus three times the SD measured from at least 10 random unstained cells. Only sections that were at least $70 \mu \mathrm{m}$ apart were considered to avoid double counting neurons. Only for presentation purposes were brightness, contrast, and curve levels of paired images (i.e., corresponding WT and AnxA2 ${ }^{-/-}$) adjusted using Photoshop CS6 (Adobe).

$D R G$ culture and nucleofection. Preparation and culture of mouse DRG neurons were performed as described previously (Coste et al., 2010) with the following modifications: growth medium (Hams F12/DMEM 1:1 ratio with L-glutamine; Gibco) was supplemented with $10 \%$ horse serum and $100 \mathrm{ng} / \mathrm{ml} \mathrm{NGF}, 50 \mathrm{ng} / \mathrm{ml} \mathrm{GDNF}, 50 \mathrm{ng} / \mathrm{ml}$ BDNF, $50 \mathrm{ng} / \mathrm{ml} \mathrm{NT}-3$, and $50 \mathrm{ng} / \mathrm{ml} \mathrm{NT-4}$. Neurons were plated on poly-D-lysine-coated coverslips, which were additionally coated with laminin $(20 \mu \mathrm{g} / \mathrm{ml})$.

Transfection of neurons was achieved by nucleofection of cDNA into freshly isolated DRG neurons using the P3 Primary Cell 4D Nucleofector $\mathrm{X}$ Kit with the 4D-Nucleofector X Unit according to the manufacturer's instructions (Lonza AG). (1) For calcium imaging rescue experiments 0.8 $\mu \mathrm{g}$ of mAnxA2-pCMVSport6 or empty pCMVSport6, each in combination with $0.2 \mu \mathrm{g}$ of pmaxGFP (Lonza AG), was to visualize transfected neurons. (2) For live labeling $0.8 \mu \mathrm{g}$ of mTRPA1-IRES-YFP was used and for rescue experiments an additional $1 \mu \mathrm{g}$ of mAnxA2-pCMVSport6 or empty pCMVSport6 was used. (3) For electrophysiology $0.5 \mu \mathrm{g}$ of mTRPA1-IRES-YFP was used. After nucleofection, neurons were allowed to recover in RPMI medium for $10 \mathrm{~min}$ at $37^{\circ} \mathrm{C}$ before plating in growth medium. Two hours after transfection half of the growth medium was exchanged with fresh medium and neurons were grown for $36-48 \mathrm{~h}$.

Quantitative PCR. Total RNA was isolated from freshly dissociated DRG neurons of AnxA2 ${ }^{-1-}$ and WT mice by NucleoSpin RNA XS (Macherey-Nagel) according to the manufacturer's instructions. One thousand nanograms of total RNA were then used for first-strand cDNA synthesis using QuantiTect reverse transcription kit (Qiagen). TRPA1 gene expression was assessed in both genotypes by real-time qPCR using the SYBR green system (Power SYBR Green PCR Master Mix; Life Technologies) in a LightCycler 480 instrument (Roche). The melting curve analysis of amplified product was used to confirm the specificity of qPCR assay. All samples were run in triplicate and control reactions were run without template and with the reverse-transcription reaction reagents as negative controls. Threshold cycle $(\mathrm{Ct})$ values, the cycle number in which SYBR green fluorescence rises above background, were normalized to two reference genes ( $\beta$-actin and GAPDH) and recorded as a measure of initial transcript amount. Primer sequences $5^{\prime}-3^{\prime}$ are the following: TRPA1 (fw: ccatgacctggcagaatacc; rev: tggagagcgtccttcagaat), $\beta$-actin (fw: gatcaagatcattgctcctcctg; rev: cagctcagtaacagtccgcc), GAPDH (fw: caatgaatacggctacagcaac; rev: ttactccttggaggccatgt).

TRPA1 live-labeling. TRPA1 live labeling was essentially performed as described previously (Schmidt et al., 2009). Freshly dissociated neurons of AnxA2 $2^{-1-}$ mice and WT littermates were nucleofected with TRPA1IRES-YFP, AnxA2, or empty plasmid for rescue experiments and main- tained in culture for $36 \mathrm{~h}$. Surface TRPA1 was live labeled by incubating neurons with TRPA1 antibodies (1:25) for $60 \mathrm{~min}$ followed by five washes in neuronal medium and incubation with secondary antibodies conjugated to Alexa Fluor 546 (Life Technologies) at a dilution of 1:200. Neurons were washed with PBS, fixed in 2\% PFA/PBS for $20 \mathrm{~min}$, and imaged on a Zeiss Axio Observer Z1 epifluorescence microscope.

All groups to be compared were processed in parallel using the same culture preparation. The image analysis was performed as described previously (Schmidt et al., 2009) with the following change: as a reference for background signal we added ROIs in the nonlabeled area along the ROI, which delineated the periphery of each neuron. This enabled us to determine a threshold value of intensity (in AUs) above which the label was considered positive for each individual neuron.

Only for presentation purposes were brightness, contrast, and curve levels of paired images (i.e., corresponding WT and AnxA2 ${ }^{-1-}$ cells) adjusted using Photoshop CS6 (Adobe).

Mouse behavior. All animals were housed in a temperature-controlled environment under a $12 \mathrm{~h}$ light/dark cycle with food and water provided ad libitum. Behavioral tests were performed by individuals blind to genotype. In these tests 6- to 12 -week-old WT and AnxA2 ${ }^{-1-}$ littermates were used and the mice were matched for gender. AnxA2 ${ }^{-l-}$ mice were kindly provided by Katherine A. Hajjar (Ling et al., 2004). Mice were acclimatized for $30 \mathrm{~min}$ (injection paradigms) or $120 \mathrm{~min}$ (thermal and mechanical paradigm) in a transparent Plexiglas box. For injections, 10 $\mu \mathrm{l}$ of experimental agent was injected subcutaneously into the plantar surface of one hindpaw. Nocifensive behaviors were assessed by measuring the time spent licking, flicking, or lifting the injected paw for $10 \mathrm{~min}$. Vehicle injection (PBS) did not elicit any significant pain behavior in either genotype (data not shown).

Mechanical and thermal sensitivity were measured according to standard procedures (Minett et al., 2011) and according to the manufacturer's manual (Ugo Basile). In brief, mechanical sensitivity was determined upon paw withdrawal to application of a graded force $(0-10 \mathrm{~g}$ in $40 \mathrm{~s}$ for basal acute sensitivity and $0-7.5 \mathrm{~g}$ in $40 \mathrm{~s}$ for the inflammatory pain paradigm) via a dynamic aesthesiometer (Ugo Basile) to the plantar surface of both hindpaws. Paw withdrawal latencies were averaged from at least four readings per paw. To determine thermal sensitivity two different tests were used: heat and cold sensitivity.

Heat sensitivity. The paw withdrawal latency to infrared heat (set at 40) was measured using a plantar test apparatus (Hargreaves apparatus; Ugo Basile). Paw withdrawal latencies for each test were averaged from at least four readings per paw.

Cold sensitivity. A custom-made cold plate was set at $1.5^{\circ} \mathrm{C}$ and the latency to the onset of nocifensive behaviors (licking, flicking, or lifting of the injected paw) and escape behaviors (jumping) was measured. If mice did not show nocifensive behaviors (as observed often after vehicle injection) they were removed from the cold plate after $5 \mathrm{~min}$ and scored with a latency of $330 \mathrm{~s}$.

All groups to be compared were assessed in parallel. All animal experiments were approved and performed in compliance with the institutional guidelines and the guidelines of the Landesamt fuer Verbraucherschutz und Lebensmittelsicherheit of Lower Saxony.

Statistical analysis. The nonparametric Mann-Whitney test or the two-tailed unpaired Student's $t$ test was used for single comparisons, and one-way ANOVA was used for multiple comparisons (GraphPad Prism software). All values refer to mean \pm SEM; $n$ indicates the sample number, $p$ denotes the significance $\left({ }^{*} p<0.05,{ }^{* *} p<0.01,{ }^{* * *} p<0.001\right)$ and refers to the respective control in each experimental group if not noted otherwise.

\section{Results \\ Unbiased MS-based identification of AnxA2 as a binding partner of TRPA1 in sensory neurons}

TRPA1 membrane abundance and function might be regulated by protein-protein interactions within the yet to be identified TRPA1 protein scaffold in sensory neurons. To test this hypothesis we first identified candidate TRPA1 interactors by affinity purification of native TRPA1 channels from mouse sensory neu- 
A

\begin{tabular}{llllc}
$\begin{array}{l}\text { Accession } \\
\text { number }\end{array}$ & Protein name & $\begin{array}{l}\text { Identified } \\
\text { peptides }\end{array}$ & $\begin{array}{l}\text { No. of } \\
\text { spectra in } \\
\text { experimental } \\
\text { replicates }\end{array}$ & $\begin{array}{l}\text { No. of } \\
\text { spectra } \\
\text { in control } \\
\text { replicates }\end{array}$ \\
\hline Q8BLA8 & TRPA1 & $\begin{array}{l}\text { FLLSQGANPNLR } \\
\text { CMALHFAATQGATDIVK } \\
\text { EVIQIFQQK } \\
\text { IAMQVELHTNLEK } \\
\text { LLQDISDTR }\end{array}$ & 7 & 0 \\
\hline P07356 & Annexin A2 & $\begin{array}{l}\text { DALNIETAVK } \\
\text { DIISDTSGDFR } \\
\text { QDIAFAYQR } \\
\text { TNQELQEINR }\end{array}$ & 5 & 0 \\
& & & \\
& & & \\
\end{tabular}

B

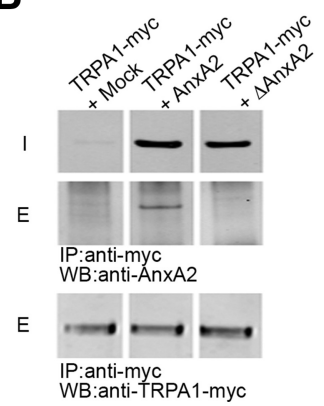

C

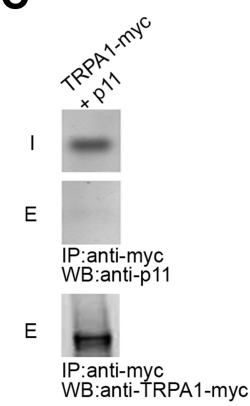

D

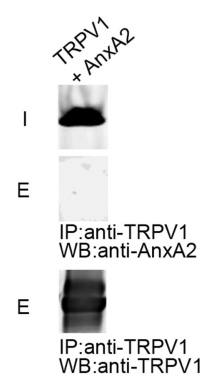

Figure 1. AnxA2 physically binds to TRPA1. A, AnxA2 coimmunoprecipitates with native TRPA1 from mouse sensory neurons as identified by MS/MS. The table depicts the MS/MS results (identified peptides and number of total spectra) of two independent TRPA1-affinity purifications and corresponding controls. $\boldsymbol{B}-\boldsymbol{D}$, Representative Western blots (WB) of immunoprecipitation (IP) experiments in HEK293T cells recombinantly expressing the indicated constructs. $\boldsymbol{B}$, AnxA2 is detected in eluates (E) of immunoprecipitations only upon cotransfection of TRPA1myc and AnxA2 (TRPA1-myc + AnxA2) but not in control conditions (TRPA1-myc + Mock). A deletion construct of $A n x A 2$ lacking the first 15 aa $(\triangle A n x A 2)$ did not coimmunoprecipitate with TRPA1 (TRPA1-myc $+\Delta$ AnxA2). Immunoprecipitations were performed with myc antibodies. C, P11 did not coimmunoprecipitate with TRPA1 in our assay (TRPA1-myc + p11). Immunoprecipitations were performed with myc antibodies. D, AnxA2 did not coimmunoprecipitate with TRPV1 in cotransfected HEK293T cells (TRPV1 + AnxA2) while TRPV1 itself is readily immunoprecipitated (TRPV1 is represented by the double band). Immunoprecipitations were performed with TRPV1 antibodies. I, input. Western blots were probed as indicated.

rons. Whole-cell lysates were obtained by detergent solubilization and endogenous TRPA1 was affinity purified using specific TRPA1 antibodies (Schmidt et al., 2009) and rabbit IgG serving as control. Eluates were separated by 1D-PAGE, gel lanes were excised, subjected to "in-gel" digestion with trypsin, and bound proteins were analyzed by MS. This procedure enabled us to detect endogenous TRPA1 channels validating our approach (Fig. 1A).

To consider potential candidates for further characterization we selected proteins that (1) appeared in both independent biological replicates of the experiment, (2) were identified with a minimum of two unique peptides, and (3) were absent in both independent control replicates. This strategy led to the identification of Annexin A2 as a binding partner of TRPA1 (Fig. 1A). AnxA2 belongs to the large family of Annexins, which are known to function as $\mathrm{Ca}^{2+}$-effector proteins and are involved in different membrane transport processes (Rescher and Gerke, 2004; Gerke et al., 2005).

\section{AnxA2 coimmunoprecipitates with TRPA1 in a heterologous expression system}

We performed several experiments to validate AnxA2 as a bona fide TRPA1 interacting protein. First, we performed immunoprecipitation experiments by transfecting HEK293T cells with myc-tagged TRPA1 (TRPA1-myc) and mouse AnxA2. We de-

tected AnxA2 when both anti-myc (Fig. 1B) and anti-TRPA1 antibodies (data not shown) were used to immunoprecipitate TRPA1-myc. HEK293T cells transfected with TRPA1-myc and the empty vector were used as a negative control (TRPA1 + Mock; Fig. $1 B$ ). In an attempt to identify the AnxA2 domain involved in the association with TRPA1, we deleted the first 15 aa of AnxA2 ( $\triangle$ AnxA2), a region implicated in AnxA2 protein-protein interactions (He et al., 2008). As shown in Figure $1 B$, the truncated form of AnxA2 did not coimmunoprecipitate with TRPA1 in our assay. This finding suggests that the first 15 aa of AnxA2 contribute to binding TRPA1 channels either directly or via yet to be identified proteins.

AnxA2 is often found in a multimeric complex with its binding partner p11 (also known as S100A10), which is a member of the EF-Hand superfamily of calcium-binding S100 proteins (Gerke et al., 2005; He et al., 2008). P11 in turn has been reported to interact with several ion channels (Okuse et al., 2002; Donier et al., 2005; Svenningsson et al., 2006), among them some TRP channels, like TRPV4 (Ning et al., 2012), TRPV5, and TRPV6 (van de Graaf et al., 2003). To test whether p11 binds to TRPA1, we performed immunoprecipitations in HEK293T cells cotransfected with TRPA1 and p11. Consistent with our proteomics data in sensory neurons we did not observe an interaction between p11 and TRPA1 (Fig. 1C).

In complementary experiments, we did not detect an association between AnxA2 and TRPV1 (Fig. 1D), a TRP channel which is highly coexpressed with TRPA1 in sensory neurons and has been shown to interact with TRPA1 (Staruschenko et al., 2010).These results demonstrate that AnxA2 physically associates with TRPA1 channels and suggest a certain degree of specificity for this interaction.

\section{AnxA2 does not affect biophysical properties of recombinant TRPA1 channels}

The association of AnxA2 with TRPA1 prompted us to test whether AnxA2 affects the biophysical properties of TRPA1 channels expressed in HEK293T cells, a well established system to assess TRPA1 activity (Bandell et al., 2004; Jordt et al., 2004; Macpherson et al., 2007; Meseguer et al., 2014). First, we transfected HEK293T cells either with TRPA1 (TRPA1 + Mock) or with TRPA1 and AnxA2 (TRPA1 + AnxA2) and measured the intrinsic voltage-dependent activation properties of TRPA1 channels upon membrane depolarization using whole-cell patchclamp recordings (Zhou et al., 2013; Meseguer et al., 2014). As shown in Figure 2, AnxA2 expression did not change the intrinsic voltage-dependent activation profile of TRPA1 channels (Fig. $2 A, B$ ). TRPA1 current density measured at $-75 \mathrm{mV}$ (following depolarization at $+175 \mathrm{mV}$ ) was not affected by AnxA2 overexpression (TRPA1 + Mock: $71.8 \pm 6.9 \mathrm{pA} / \mathrm{pF}$; TRPA1 + AnxA2: $75.3 \pm 8.1 \mathrm{pA} / \mathrm{pF}$, n.s., Student's $t$ test; $n=12$ cells per condition). Furthermore, neither activation nor inactivation time constants were different when AnxA2 was present (TRPA1 + Mock: $19.3 \pm 4.3$ and $46.7 \pm 3.1 \mathrm{~ms}$; TRPA1 + AnxA2: $19.3 \pm 5.5$ and $52.6 \pm 6.1 \mathrm{~ms}$, for activation and inactivation, respectively; n.s., Student's $t$ test; $n=12$ cells per condition). Next, we studied the activation properties of TRPA1 channels upon application of MO, a specific TRPA1 agonist (Bandell et al., 2004; Bautista et al., 2006; Macpherson et al., 2007; Zhou et al., 2013). None of the measured parameters, i.e., activation as well as inactivation time constants and the MO-dependent $I / V$ relation of TRPA1 were altered by AnxA2 overexpression (Fig. 2C,D).

In a complementary approach we used ratiometric calcium imaging to monitor whether AnxA2 influences the increase of 
intracellular calcium levels $\left[\mathrm{Ca}^{2+}\right]_{\mathrm{i}}$ upon TRPA1 activation (Fig. 2E,F). Figure $2 F$ shows that TRPA1 activation by MO induced a similar dose-dependent and reversible increase of $\left[\mathrm{Ca}^{2+}\right]_{i}$ in both transfection conditions (effective concentrations: TRPA1 + Mock: $9.2 \pm 2.1 \mu \mathrm{M}$; TRPA1 + AnxA2: $6.2 \pm 0.9 \mu \mathrm{M} ; p=$ 0.2683 ; n.s., Student's $t$ test). Changes in $\left[\mathrm{Ca}^{2+}\right]_{\mathrm{i}}$ were dependent on the presence of TRPA1 as nontransfected cells did not respond to $\mathrm{MO}$ (Fig. 2E).

Collectively these findings show that AnxA2 overexpression does not grossly alter TRPA1 channels in HEK293T cells.

\section{AnxA2 is coexpressed with TRPA1 in nociceptors}

Subsequently we turned to investigate the potential relevance of AnxA2 for TRPA1dependent nociceptive signaling in a physiological cellular setting, i.e., sensory neurons of DRG.

To this end, we first determined the expression pattern of AnxA2 in sensory neurons of rodent DRG. DRG neurons are highly heterogeneous including a subset of small-diameter, non-myelinated Peripherin-positive neurons that transmit nociceptive signals (Patapoutian et al., 2009). We observed AnxA2 expression in $30.1 \pm 1 \%$ of mouse DRG neurons ( 3000 neurons were analyzed) of which $66 \pm$ $1.7 \%$ showed coexpression with Peripherin (Fig. 3A). This enriched expression of AnxA2 in a subpopulation of small nonmyelinated neurons matches with nociceptors, i.e., sensory neurons mediating nociceptive signaling (Patapoutian et al., 2009), and is consistent with earlier reports (Naciff et al., 1996). Importantly, the observed AnxA2 label was specific, as AnxA2-deficient mice (AnxA2 ${ }^{-1-}$; Ling et al., 2004) were devoid of it (Fig. 3B). If AnxA2 binds to TRPA1 channels, it should be coexpressed with TRPA1 in nociceptors. As antibodies against TRPA1 and AnxA2 are both derived from rabbit they could not be used for colocalization studies. Therefore, we turned to using a mouse AnxA2 antibody in rat DRG neurons. Similarly to mouse DRG, AnxA2 is expressed in $27 \pm 0.7 \%$ of rat DRG neurons ( 9000 neurons analyzed) of which $68 \pm 1.9 \%$ coexpressed Peripherin and $5 \pm 0.5 \%$ NF200, a marker for myelinated neurons (Fig. $3 C, D)$. Furthermore, we detected TRPA1 label in $16.2 \pm 1.5 \%$ of rat DRG neurons, which is in line with published data using the same antibodies (Schmidt et al., 2009) and different TRPA1 antisera (Bautista et al., 2005). Interestingly, $53 \pm 1.4 \%$ of TRPA1positive neurons (5000 neurons analyzed) also expressed AnxA2 indicating coexpression of both proteins in a subpopulation of rat DRG neurons (Fig. 3E). Of note, the actual degree of coexpression cannot be unambiguously determined, as data from previous studies and those presented here suggest that TRPA1

E
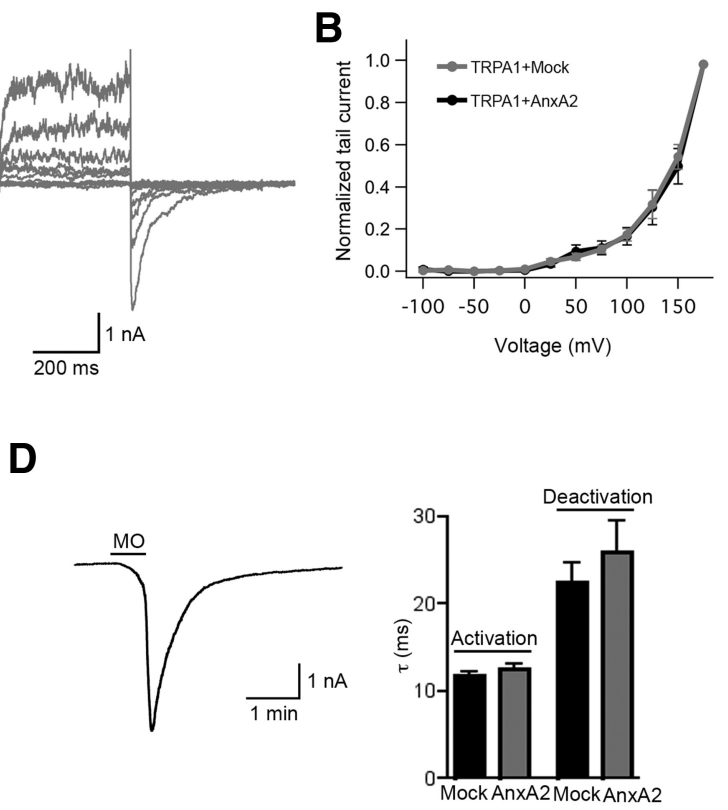

Figure 2. AnxA2 neither affects TRPA1 voltage dependence nor cellular responses to the TRPA1 agonist MO. $A, B$, AnxA2 does not affect the voltage dependence of TRPA1. $A$, Whole-cell currents in response to voltage steps applied to HEK293T cells expressing TRPA1 (TRPA1 + Mock) or TRPA1 + AnXA2. B, Average \pm SEM voltage dependence of TRPA1 peak tail currents at $-75 \mathrm{mV}$ maximum depolarization level ( $+175 \mathrm{mV}$ ). C, Representative currents elicited by $/ / V$ ramps after (M0) application of $25 \mu \mathrm{m} M 0$ for indicated transfections. $\boldsymbol{D}$, Left, representative M0-induced current at $-70 \mathrm{mV}$ (holding potential). Right, Average \pm SEM time

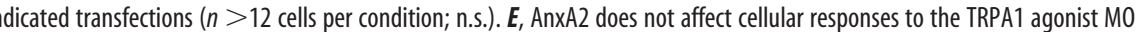

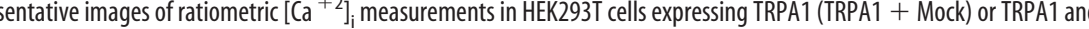
response to $10 \mu \mathrm{M} \mathrm{MO}$ (M0). One hundred micromolar ATP was applied after M0 to control for cellular health. Scale bar, $10 \mu \mathrm{m} . \boldsymbol{F}$ Dose dependency of $\mathrm{MO}$-evoked increase of cellular $\left[\mathrm{Ca}^{+2}\right]_{\mathrm{i}}$. All data are represented as mean $\pm \mathrm{SEM}$.

antibodies preferentially label neurons with relatively high TRPA1 expression (Schmidt et al., 2009; Huang et al., 2012).

Altogether these results demonstrate that AnxA2 is expressed in a TRPA1-positive subset of nociceptors and suggest a previously unrecognized role of AnxA2 in sensory neurons.

\section{AnxA2 ${ }^{-/-}$mice exhibit augmented TRPA1 expression in sensory neurons}

After having shown that AnxA2 is present in nociceptors, we evaluated the consequences of AnxA2 deletion for different subpopulations of sensory neurons. To this end we compared the expression of TRPA1 and several markers for DRG neuron subpopulations by immunohistochemistry between $\mathrm{AnxA} 2^{-1-}$ mice and WT littermates. Interestingly, AnxA2 $2^{-1-}$ mice exhibited a significant increase in the number of TRPA1-positive neurons compared with WT littermates (WT: $8.1 \pm 0.4 \%$; AnxA2 ${ }^{-1-}$ : 
A

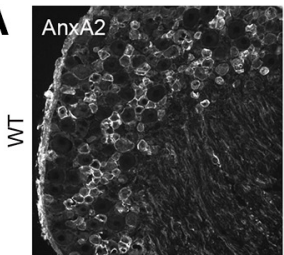

B

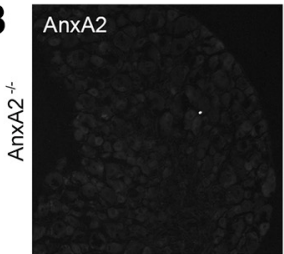

C
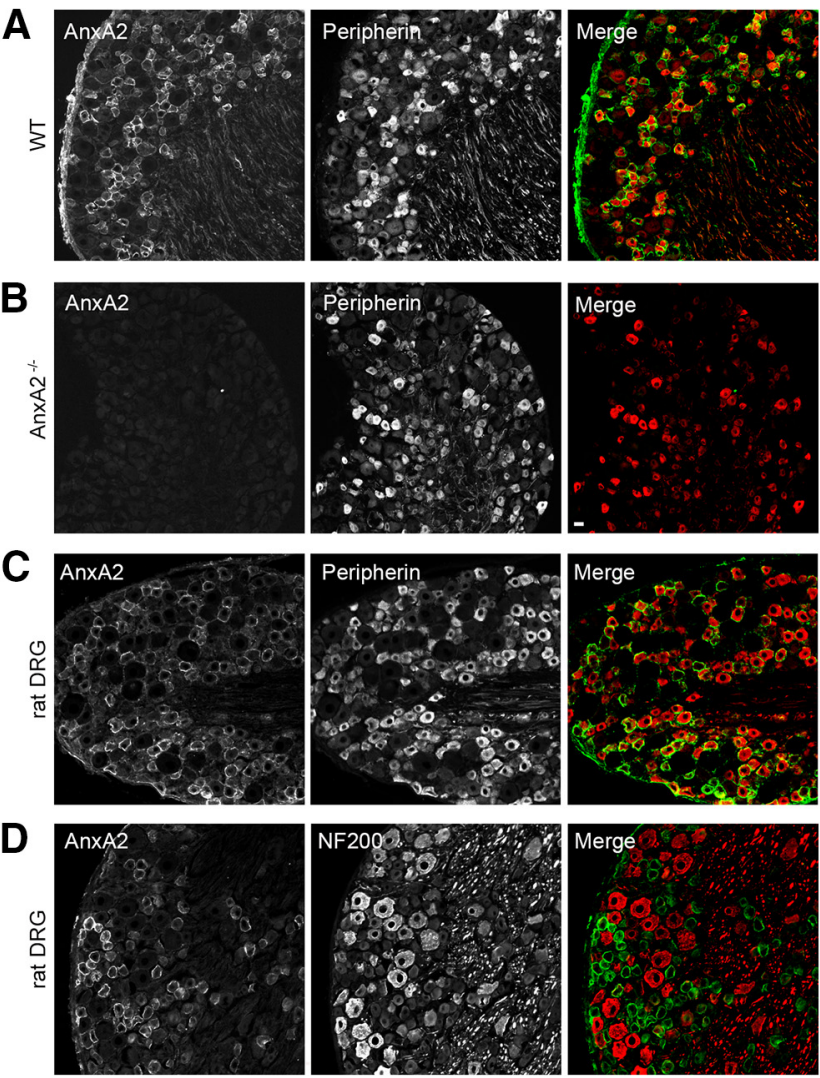

$\mathbf{E}$
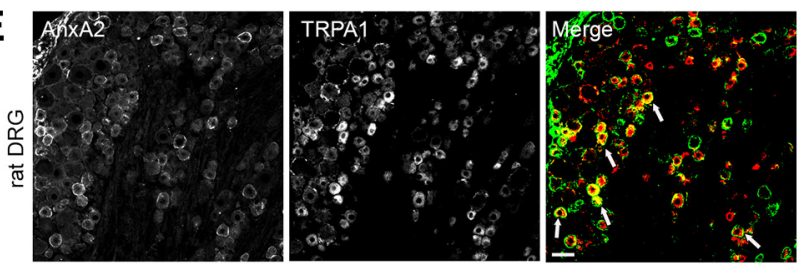

Figure 3. AnxA2 is coexpressed with TRPA1 in nociceptors. $A, B$, Representative images of immunohistochemistry on cryosections of mouse DRG colabeled for AnxA2 and Peripherin in WT mice $(\boldsymbol{A})$ and AnxA2 ${ }^{-1-}(\boldsymbol{B})$ littermates. Scale bar, $20 \mu \mathrm{m}$. $\boldsymbol{C}-\boldsymbol{E}$, Representative images of immunohistochemistry on cryosections of rat DRG colabeled for AnxA2 and Peripherin, NF200, or TRPA1, respectively. White arrows indicate examples of neurons coexpressing AnxA2 and TRPA1. Scale bar, $40 \mu \mathrm{m}$.

$13.6 \pm 0.5 \% ; 3000$ neurons analyzed; $p=0.0009$, Student's $t$ test; Fig. 4). In contrast, neither Trpa1 mRNA levels (as determined by qPCR in DRG; data not shown) nor the prevalence of immunoreactive neurons for Peripherin, NF200, and TRPV1 were different between genotypes (Fig. 4). Importantly, the obtained values for TRPA1 expression in WT mouse DRG are in accordance with published data using the same antibodies (Schmidt et al., 2009; Huang et al., 2012) while studies using in situ hybridization are controversial and report a range of 3.6-56\% of mouse DRG neurons expressing Trpal mRNA (Story et al., 2003; Nagata et al., 2005; Malsch et al., 2014).

These data suggest a specific increase of TRPA1 label in AnxA2 $2^{-1-}$ mice without generally affecting neuron-type specification in sensory neurons.

TRPA1 responses are sensitized in a subset of AnxA2 ${ }^{-1-}$ sensory neurons

The higher number of TRPA1-immunoreactive neurons in AnxA2 ${ }^{-1-}$ mice could be due to (1) TRPA1 de novo expression in additional neurons compared with WT or (2) increased TRPA1
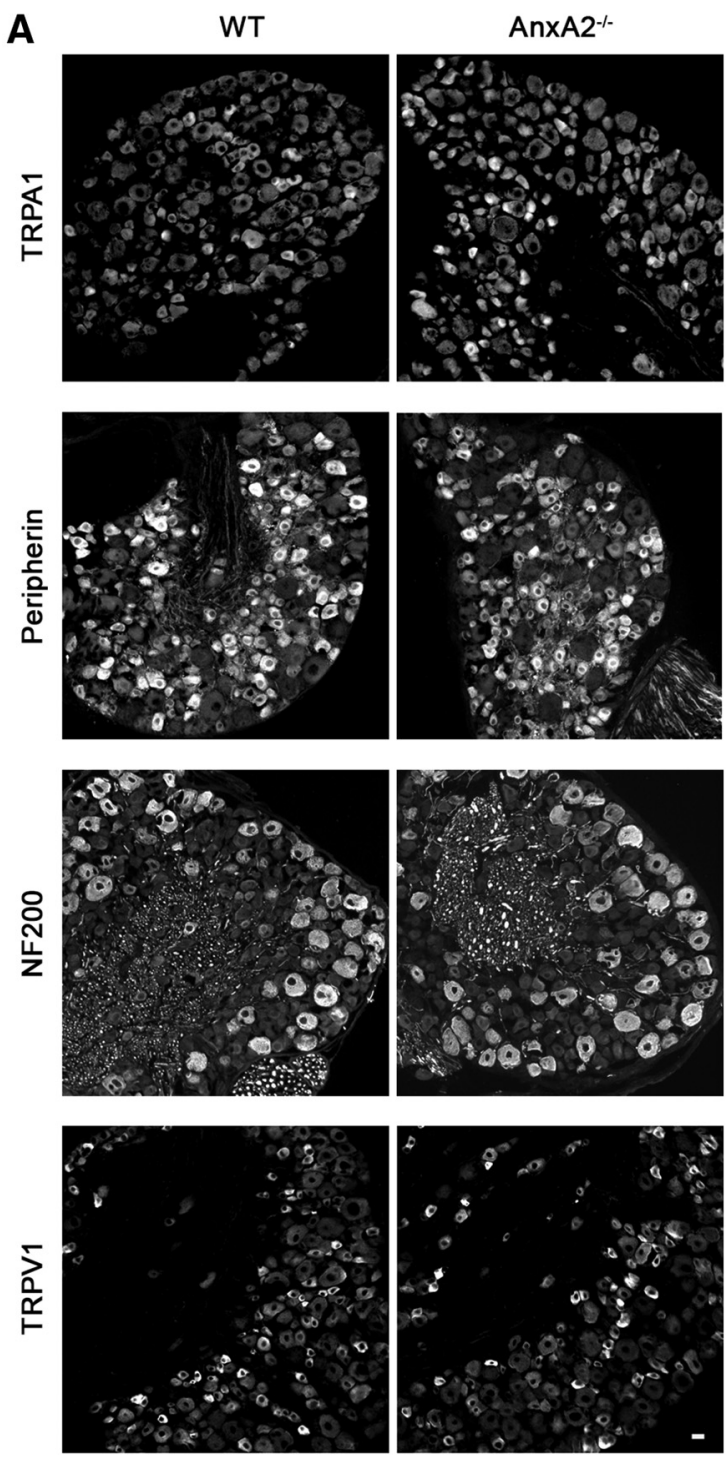

B

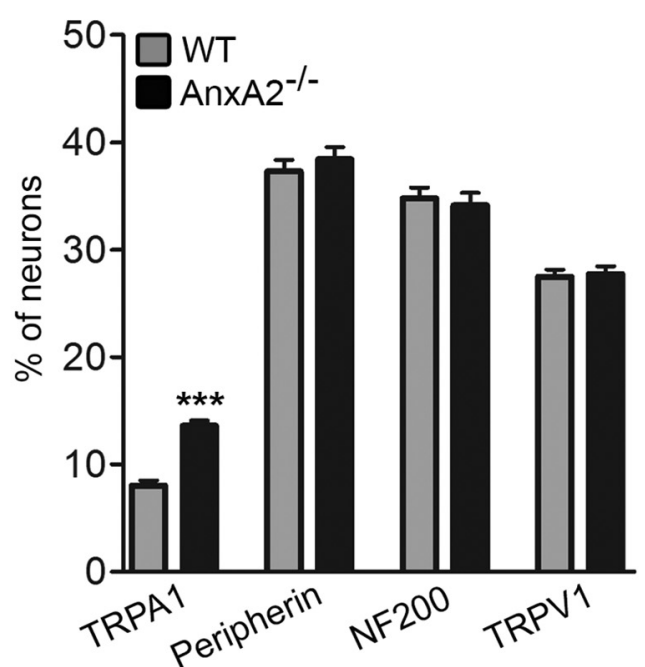

Figure 4. AnxA2 ${ }^{-1-}$ mice exhibit more TRPA1-positive DRG neurons. $A, B$, Representative images $(\boldsymbol{A})$ and quantification $(\boldsymbol{B})$ of immunohistochemistry on DRG cryosections from AnxA2 ${ }^{-1-}$ mice and WT littermates labeled for TRPA1, Peripherin, NF200, and TRPV1 as indicated. Scale bar, $20 \mu \mathrm{m}$. All data are represented as mean \pm SEM. 

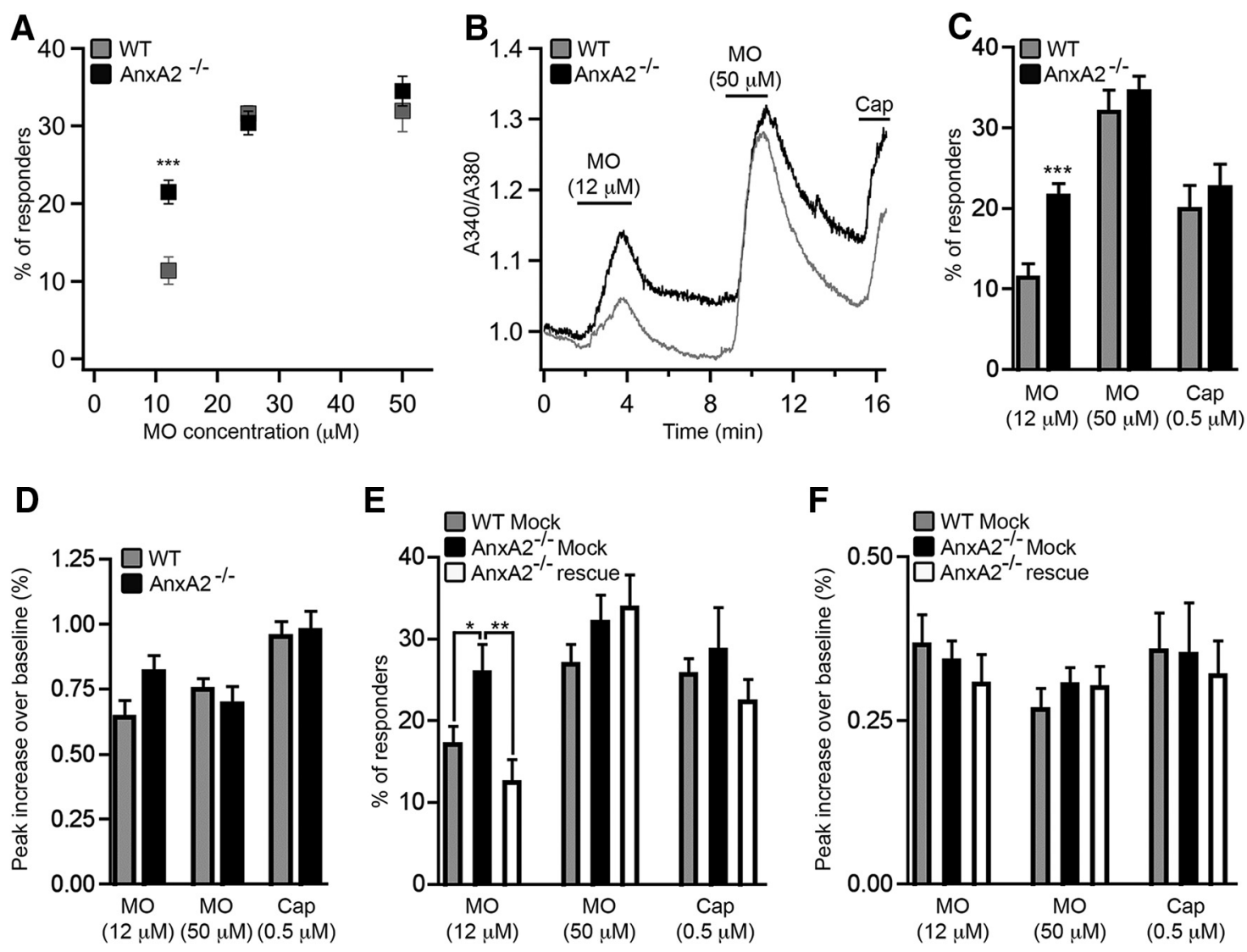

Figure 5. TRPA1 responses are sensitized in a subset of $A n \times A 2^{-/-}$sensory neurons. $\boldsymbol{A}-\boldsymbol{F}, A n x A 2^{-/-}$DRG cultures are more sensitive to low $M 0$ concentrations as measured by ratiometric calcium imaging. $\boldsymbol{A}$, The graph depicts the percentage of responders to $12 \mu \mathrm{M}, 25 \mu \mathrm{M}$, or $50 \mu \mathrm{M} \mathrm{M0}\left(12 \mu \mathrm{M}\right.$, AnxA2 ${ }^{-1-}: 21.5 \pm 1.5$ compared with WT: $11.4 \pm 1.7, p=0.0008$, Student's $t$ test; $n \geq 500$ neurons for each $\mathrm{M} 0$ concentration from $N=3$ independent cultures each). $\boldsymbol{B}$, Representative averaged traces from all neurons in one coverslip (including responders and nonresponders to applied stimuli) upon application of indicated stimuli. C, Quantification of the percentage of neurons responding to each stimulus (M0; $12 \mu \mathrm{m}$, see data in $A ; 50 \mu \mathrm{m}$, AnxA2 ${ }^{-/-}: 34.5 \pm 1.9$ compared with WT: $32 \pm 2.7$, n.S.; Cap $0.5 \mu \mathrm{m}$, AnxA2 ${ }^{-/-}: 22.6 \pm 2.8$ compared with WT: $19.9 \pm 2.9$, n.S.; $n=560$ WT and 640 AnxA2 ${ }^{-/-}$neurons, $N=3$ independent cultures each). $\boldsymbol{D}$, Quantification of response amplitudes to each stimulus (measured as peak increase over baseline). $\boldsymbol{E}, \boldsymbol{F}$, Quantification of the percentage of neurons responding to each stimulus ( $\boldsymbol{E}$ ) and the response amplitudes $(\boldsymbol{F})$ in Mock-transfected WT neurons (WT Mock), Mock-transfected AnxA2 ${ }^{-/-}$neurons (AnxA2 ${ }^{-/-}$Mock), and AnxA2 ${ }^{-/-}$neurons transfected with AnxA2 cDNA (AnxA2 ${ }^{-/-}$rescue). Twelve micromolar M0 (WT Mock: $17.1 \pm 2.2$, AnxA2 ${ }^{-1-}$ Mock: $25.9 \pm 3.4$, AnxA2 ${ }^{-1-}$ rescue: $12.4 \pm 2.8{ }^{*}{ }^{*} p<0.05,{ }^{* *} p<0.01$, ANOVA with Newman-Keuls test; $n=292$ WT Mock, 275 AnxA2 ${ }^{-I-}$ Mock, and $269 \mathrm{AnxA2}^{-1-}$ rescue neurons, $N=3$ independent cultures each). (ap, capsaicin.

levels in some neurons facilitating detection by TRPA1 antibodies. Indeed, TRPA1 antibodies have been described to exhibit limited sensitivity and therefore preferentially label neurons with high TRPA1 abundance (Schmidt et al., 2009; Huang et al., 2012). Hence antibody-dependent labeling methods on fixed tissue are not well suited for differentiating between TRPA1 de novo expression and increased cellular TRPA1 abundance.

For that reason we turned to an antibody-independent and well established approach to investigate TRPA1 channels by using ratiometric calcium imaging in cultured sensory neurons from mouse DRG (Bautista et al., 2006; Schmidt et al., 2009). We used the specific TRPA1 agonist MO (Jordt et al., 2004; Bautista et al., 2006) and compared the consequences of TRPAl activation between AnxA2 ${ }^{-l-}$ mice and WT littermates. Because of previous studies reporting that TRPA1 expression in DRG cultures is heterogeneous (Schmidt et al., 2009; Vandewauw et al., 2013), we applied two different concentrations of MO: (1) a subsaturating concentration ( $12 \mu \mathrm{M}$; Fig. $5 \mathrm{~A}$ ) destined to reveal the subset of TRPA1-positive neurons, which are abundantly expressing TRPA1, and (2) a saturating pulse ( $50 \mu \mathrm{M}$; Fig. $5 A)$, which activates the whole TRPA1-positive neuron population and therefore enables its quantitative comparison between genotypes (Jordt et al., 2004; Zhou et al., 2013). Interestingly, in AnxA2 ${ }^{-1-}$ cultures more neurons responded to $12 \mu \mathrm{M}$ MO compared with cultures from WT littermates (Fig. 5A, B), which may be indicative of higher TRPA1 expression in these neurons. In contrast, we did not detect any difference between genotypes when $50 \mu \mathrm{M} \mathrm{MO}$ was used to reveal the total amount of neurons expressing TRPA1 (Fig. 5A,B). The latter result reveals that the total number of TRPA1-expressing neurons is not changed in AnxA2 ${ }^{-1-}$ DRG. Together with the facts that we did not see any differences among genotypes in respect to (1) TRPV1-mediated responses to the TRPV1-specific agonist capsaicin (Cap; Fig. $5 B, C$ ), (2) the amplitudes to each tested agonist (Fig. 5D), and (3) TRPA1 desensitization by $\mathrm{MO}$ or cross-desensitization by Cap (data not shown), the results suggest that AnxA2 deletion may specifically affect TRPA1 in a subset of AnxA2 ${ }^{-/-}$DRG neurons.

To test whether our observations are dependent on AnxA2 we performed a rescue experiment and transfected AnxA2 ${ }^{-1-}$ DRG cultures with recombinant mAnxA2 or control plasmid (Mock) by nucleofection. Expression of AnxA2 in AnxA2 ${ }^{-1-}$ cultures restored the number of responders upon application of $12 \mu \mathrm{M}$ MO to WT values, whereas again the responsiveness to $50 \mu \mathrm{M}$ MO or Cap (Fig. $5 E$ ) and the response amplitudes were similar among genotypes (Fig. 5F).

Overall, these experiments point toward a role of AnxA2 distinctly modulating native TRPA1 channels in a subset of sensory 
A
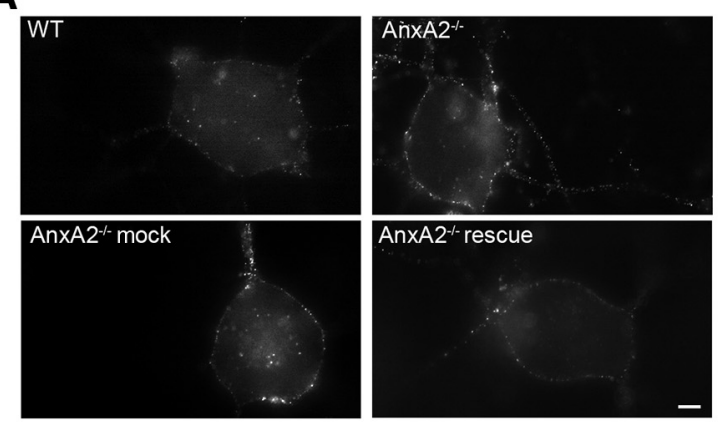

C

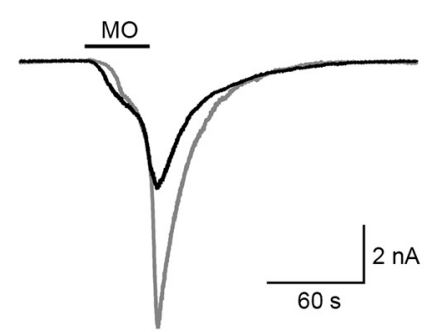

B

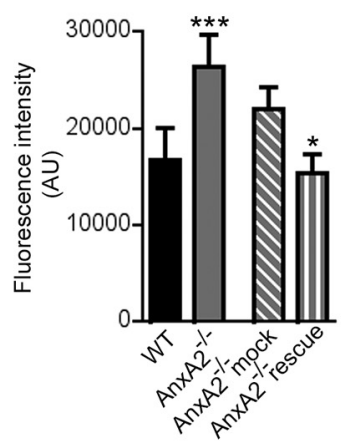

D

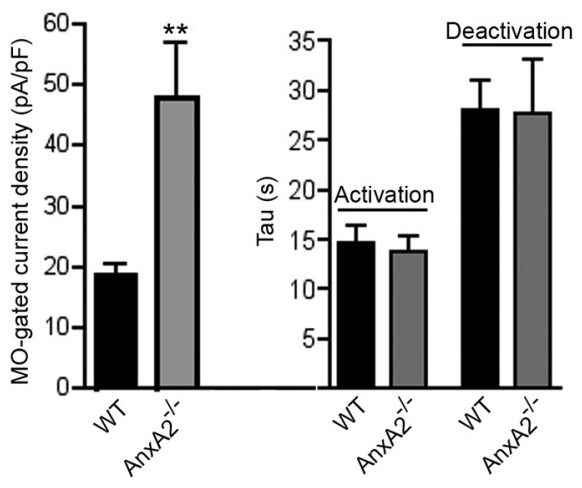

Figure 6. AnxA2 restricts TRPA1 membrane levels in cultured DRG neurons. $\boldsymbol{A}, \boldsymbol{B}, \mathrm{DRG}$ cultures from $\mathrm{AnxA2} 2^{-/-}$mice and WT littermates were nucleofected with mTRPA1 (top) or conucleofected with AnXA2 CDNA (AnxA2 ${ }^{-1-}$ rescue; control: AnxA2 ${ }^{-1-}$ Mock; bottom) and subjected to live labeling to selectively visualize TRPA1 channels at the plasma membrane. Representative images $(\boldsymbol{A}$, taken at the bottom of the coverslip) and quantification $(\boldsymbol{B})$ of live labeling (TRPA1 nucleofection: $p=0.0004$, Mann-Whitney test; $n=50$ cells per genotype, $N=5$ independent cultures each; AnxA2/Mock conucleofection: $p=0.0115$, Mann-Whitney test; $n=40$ cells per genotype, $N=4$ independent cultures each). Scale bar, $10 \mu \mathrm{m}$. All data are represented as mean \pm SEM. C, Representative whole-cell current traces of M0-gated currents at $-70 \mathrm{mV}$ in DRG neurons nucleofected with mTRPA1 (black trace: WT; gray trace: AnxA2 ${ }^{-1-}$ ). The upper bar indicates the addition of $5 \mu \mathrm{M} M 0$ to the recording chamber. $\boldsymbol{D}$, Left, Average \pm SEM of current density after M0 application measured at the current peak in each genotype $(p=0.007$, Student's $t$ test; $n>12$ neurons; $N=3$ cultures each). Right, Time constants of M0-induced activation and inactivation measured by a mono-exponential fit to the currents obtained at $-70 \mathrm{mV}$ for each genotype (n.s.; $n>12$ neurons; $N=3$ cultures each).

neurons while the prevalence of TRPA1- and TRPV1-expressing neurons was unaltered.

\section{AnxA2 limits the membrane availability of TRPA1 in sensory neurons}

How could one explain the higher number of responders in AnxA2 ${ }^{-1-}$ DRG cultures compared with WT cultures only at low MO concentrations? As mentioned above, DRG neurons are very heterogeneous regarding TRPA1 expression levels. Therefore, low agonist concentrations might reveal those TRPA1-positive neurons that exhibit higher TRPA1 expression at the plasma membrane and consequently display increased responsiveness to MO.

To test this, we aimed at live labeling surface TRPA1 channels in AnxA2 ${ }^{-1-}$ and WT DRG cultures. Currently available TRPA1 antibodies are not suitable to effectively label the low-abundant native TRPA1 population in DRG cultures under normal conditions. Therefore, we nucleofected DRG neuronal cultures of both genotypes with recombinant mTRPA1 and live labeled TRPA1 channels at the cell surface. In line with our hypothesis, AnxA2 ${ }^{-1-}$ neurons exhibited an increase of TRPA1 label at the plasma membrane, which was rescued by AnxA2 re-expression (Fig. $6 A, B)$. Moreover, $\mathrm{MO}$ application elicited bigger TRPA1 currents in AnxA2 ${ }^{-1-}$ DRG neurons nucleofected with recombinant mTRPA1 compared with nucleofected WT neurons, while activation and de- activation time constants were similar between genotypes (Fig. 6C,D).

In combination with the calciumimaging data in sensory neurons (Fig. 5), these findings consistently suggest that AnxA2 restricts TRPA1 levels at the plasma membrane of DRG neurons.

\section{TRPA1-dependent nocifensive}

\section{behaviors are enhanced in}

AnxA2 ${ }^{-1-}$ mice

Several studies reported a correlation of TRPA1 expression in sensory neurons with the degree of mouse nocifensive behaviors in pain paradigms (Obata et al., 2005; Schmidt et al., 2009; Zhou et al., 2013). Therefore, we asked whether the regulation of TRPA1 membrane levels by AnxA2 has functional consequences for TRPA1-dependent nociception. For this, we explored the physiological consequences of AnxA2 knockdown in four different mouse pain paradigms: acute thermal, mechanical and chemical sensitivity as well as inflammatory pain.

Neither acute sensitivity to thermal (measured by the Hargreaves apparatus) nor to innocuous mechanical stimuli (measured by a dynamic plantar aesthesiometer) were different between AnxA2 ${ }^{-1-}$ mice and WT littermates (Fig. 7A). In contrast, we detected a significant increase of TRPA1-dependent nocifensive responses (Kwan et al., 2006) to an intraplantar injection of $\mathrm{MO}$ in AnxA2 ${ }^{-1-}$ mice compared with WT littermates (Fig. 7B). Interestingly, this difference was dependent on the concentration of $\mathrm{MO}$, with high MO concentrations $(60 \mathrm{~mm}$, a concentration upon which we see strong and long-lasting nocifensive behavior in WT mice) eliciting equally pronounced nocifensive responses in AnxA2 $2^{-1-}$ mice and WT littermates (Fig. 7B). Importantly, capsaicin injections, which probe TRPV1-dependent nociception (Caterina et al., 2000), did not reveal any difference between genotypes (Cap; Fig. 7B).

Many studies have highlighted the contribution of TRPA1 to certain states of hyperalgesia under conditions of inflammatory pain (Obata et al., 2005; Bautista et al., 2006; Petrus et al., 2007; da Costa et al., 2010; del Camino et al., 2010; Zhou et al., 2013). Therefore, we investigated the possible impact of AnxA2 on TRPA1 function during inflammatory pain using the widely used CFA model in mice (Obata et al., 2005; Petrus et al., 2007; da Costa et al., 2010; Zhou et al., 2013). In WT mice, unilateral intraplantar injection of CFA induces thermal (to cold and hot temperatures) and mechanical hypersensitivity (Fig. 7C,D) within $2 \mathrm{~d}$. In this time frame TRPA1 has been shown to contribute to cold hypersensitivity (Obata et al., 2005; da Costa et al., 2010), while it is dispensable for heat hypersensitivity (Bautista et al., 2006; Petrus et al., 2007) and its role for innocuous mechanical hypersensitivity is debated (Petrus et al., 2007; da Costa et al., 2010; Zhou et al., 2013). In line with AnxA2 controlling TRPA1 channels, we observed enhanced sensitivity on a cold plate (Fig. 7C) but normal sensitivity to innocuous heat and mechanical 
stimulation (Fig. 7D) upon injection of CFA into one hindpaw of AnxA2 ${ }^{-/-}$ mice.

These in vivo results demonstrate that AnxA2 influences TRPA1-dependent nociception in mice.

\section{Discussion}

TRPA1 channels have been the subject of intensive investigation due to their key role in pain and inflammatory disorders in vertebrates. Nonetheless, the endogenous molecular mechanisms regulating TRPA1 function are largely unknown. We performed an unbiased proteomics approach to search for proteins associated with native TRPA1 channels in sensory neurons and report here on the identification of AnxA2 as a binding partner of TRPA1. Using a combination of immunohistochemistry, live labeling of surface TRPA1 channels, electrophysiology, calcium imaging, and mouse behavior our data demonstrate a role for AnxA2 controlling the membrane availability of TRPA1 in sensory neurons, and, consequently, influencing TRPA1-dependent behaviors. These results set the stage to decipher the elusive composition of TRPA1associated protein complexes and highlight their impact on TRPA1-dependent nociceptive signaling.

AnxA2 belongs to the large family of Annexins and serves as a calcium-effector protein mediating membrane trafficking events of exocytotic and endocytotic nature (Rescher and Gerke, 2004; Gerke et al., 2005). Accordingly, previous studies have shown the involvement of AnxA2 in delivering and retrieving various transmembrane proteins to and from the plasma membrane (Tamma et al., 2008; Rankin et al., 2013; Dathe et al., 2014). AnxA2 may exert these functions in its monomeric form or within a heteromeric complex together with its binding partner p11 (Mayran et al., 2003; Morel and Gruenberg, 2009). AnxA2-p11 complexes have been reported to bind several ion channels including TRPV4 (Ning et al., 2012) and Nav1.8 in DRG neurons (Okuse et al., 2002). Yet, it is p11 that provides the physical link to these ion channels and facilitates their incorporation into the plasma membrane, a mechanism potentially underlying the deficits in somatosensory coding in mice lacking p11 in DRG neurons (Foulkes et al., 2006). On the contrary, our data identify AnxA2 as a regulator of TRPA1 function. We find that TRPA1 associates to AnxA2 but not p11 in sensory neurons and in HEK293T cells. Consistent with this, reexpression of AnxA2 counteracts the observed increase in TRPA1 surface levels and neuronal sensitivity to the TRPA1 agonist MO in AnxA2 ${ }^{-1-}$ neurons.

Recently, TRPA1b, a TRPA1 isoform, has been described to increase TRPA1 levels at the plasma membrane of sensory neurons (Zhou et al., 2013). Our data unambiguously demonstrate that AnxA2 physically interacts with TRPA1 in the absence of capsaicin.
B

C
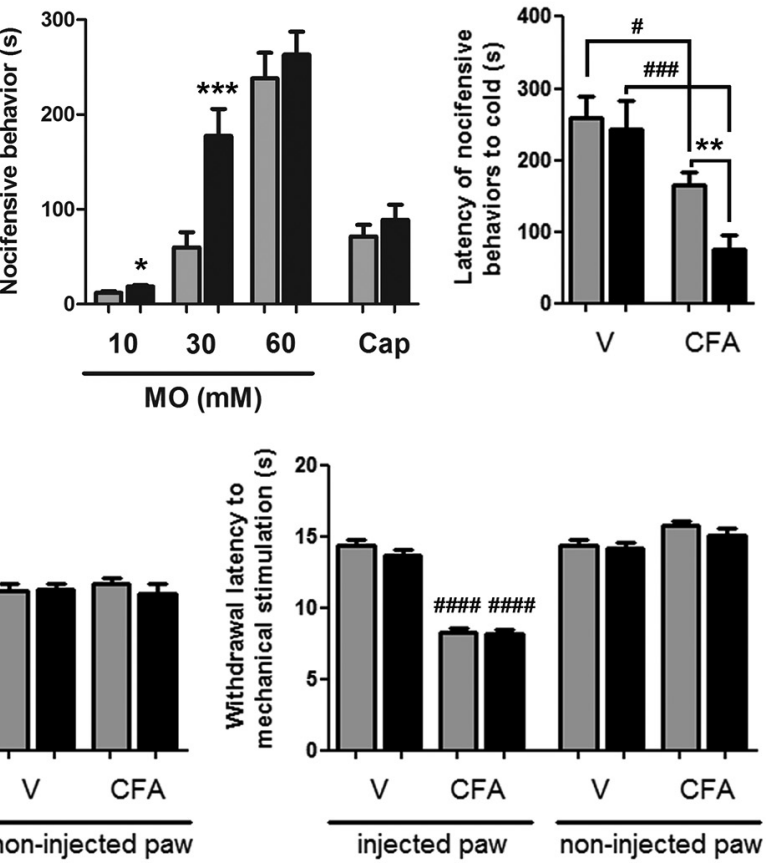
Figure 7. Enhanced TRPA1-dependent nocifensive behaviors in AnxA2
drawal of both hindpaws when WT mice and $A n \times A 2^{-1-}$ littermates were subjected to radiant heat (Heat) or punctuate mechanical pressure (Heat: $n=10$ mice each; Mechanical: $n=9$ mice each; n.S., Student's $t$ test). $\boldsymbol{B}$, Quantification of the response compared with AnxA2 ${ }^{-1-} 18.5 \pm 1.6 \mathrm{~s}, n=10$ mice each; $p=0.0126$, Student's $t$ test; $30 \mathrm{mm:} \mathrm{WT} 59.9 \pm 15.9 \mathrm{~s}, n=8$ mice $177.4 \pm 28.5 \mathrm{~s}, n=11$ mice; $p=0.0009$, Student's $t$ test; 60 mm: WT compared with AnxA2 each; $p=0.4040, n$. Student's $t$ test). inflammatory pain. C, Quantification of the latency of nocifensive/escaping behaviors when mice were placed on a cold plate $24 \mathrm{~h}$ after vehicle injection (V; $n=8$ mice each; $n . s$.) and CFA-injection (WT CFA: 165.7 $\pm 17.1 \mathrm{~s}, n=15$ mice; AnxA2 ${ }^{-1-}$ CFA:75.2 \pm $19.3 \mathrm{~s}, n=13$ mice; $^{* *} p<0.01$ comparing values of CFA of the injected paw between genotypes; ${ }^{\#} p<0.05$ and ${ }^{\# \# \#} p<0.001$

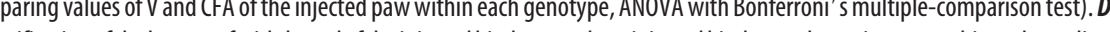
metween genotypes; Mechanical: $n=9$ mice each, n.s. between genotypes; ${ }^{\# \# \#} p<0.0001$ comparing values of

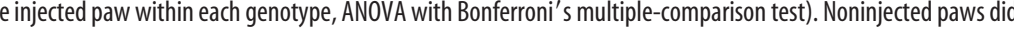

TRPA1b in a heterologous expression system. However, currently available TRPA1 antibodies are not suitable to differentiate among TRPA1 isoforms; therefore, we cannot exclude the possibility that TRPA1b might also be regulated by AnxA2 in sensory neurons.

Our study clearly demonstrates a role of AnxA2 for regulating TRPA1 channels in sensory neurons both in vitro and in vivo. The underlying mechanisms might be manifold. Previous studies have reported that TRPA1 activity, turnover, and expression can be modulated by multiple signaling pathways including growth factors like NGF (Diogenes et al., 2007), oxygen availability (Takahashi et al., 2011), inflammatory signals (Dai et al., 2007; S. Wang et al., 2008; Schmidt et al., 2009), and interaction with the splice isoform TRPA1b and TRPV1 (Akopian et al., 2007; Staruschenko et al., 2010; Zhou et al., 2013).

While the contribution of AnxA2 to each of these processes remains to be investigated, our study strongly suggests that AnxA2 limits the abundance of TRPA1 channels at the plasma membrane. In the absence of AnxA2 we observe facilitation of 
TRPA1-dependent neuronal responses (Fig. 5) and MO-gated currents (Fig. 6) along with an increase of native and recombinant TRPA1 channels at the surface of sensory neurons (Fig. 6). Furthermore, TRPA1-dependent pain behaviors are enhanced in AnxA2 $2^{-1-}$ mice, which may indicate the in vivo importance of controlling TRPA1 membrane availability for somatosensory coding.

Our coexpression analysis suggests that AnxA2 is only present in a subpopulation of TRPA1-expressing neurons. Consequently, merely this subpopulation would display AnxA2-dependent TRPA1 regulation in WT neurons. This fact may provide an explanation as to why the role of AnxA2 for TRPA1 signaling in both, neuronal cultures and in vivo, is revealed by nonsaturating concentrations of MO (i.e., concentrations that activate predominantly those neurons with higher TRPA1 abundance due to AnxA2 ablation). In contrast, upon addition of saturating $\mathrm{MO}$ concentrations, all TRPA1-expressing neurons (regardless of TRPA1 abundance) will strongly be activated and consequently result in similar neuronal and behavioral responses in WT and AnxA2 $2^{-1-}$ mice as suggested by our findings.

We and others demonstrated that AnxA2 is present in both TRPA1-positive and TRPA1-negative DRG neurons (Naciff et al., 1996). Therefore, it may modulate other proteins and signaling pathways in addition toTRPA1. Previously, TRPA1 channels have been reported to interact with TRPV1 channels and both proteins are coexpressed in a subset of sensory neurons (Akopian et al., 2007; Staruschenko et al., 2010). For this reason we especially focused on evaluating a potential effect of AnxA2 on TRPV1, which we did not find any evidence for: (1) our biochemical data indicated that AnxA2 does not physically bind to TRPV1 channels, (2) calcium responses upon capsaicin were not altered in AnxA2 ${ }^{-1-}$ mice compared with WT littermates, (3) the number of sensory neurons expressing TRPV1 was not changed, and (4) pain behaviors to intraplantar injection of capsaicin and to heat did not differ between genotypes. This specificity suggests a quite distinct role of AnxA2 for TRPA1-dependent nociception.

Additional evidence that nociception is not generally perturbed in AnxA2 ${ }^{-1-}$ mice stems from the fact that their responsiveness to heat and mechanical stimulation is preserved. Moreover, both acute nocifensive behaviors tested in our study (injection of $\mathrm{MO}$ and Caps) require transmission via primary afferent nociceptors followed by supraspinal processing (X. Wang et al., 2013). Therefore, the selective alteration of MOinduced behaviors argues against gross changes in supraspinal processing of pain messages in AnxA2 $2^{-1-}$ mice.

In conclusion, we identified AnxA2 as a novel TRPA1associated protein that regulates TRPA1 channels in vitro and in vivo. The findings presented here underscore the idea that TRPA1 surface availability is controlled by protein-protein interactions and influences nociceptive signaling in sensory neurons. AnxA2 has been reported to undergo changes in abundance during inflammatory and neuropathic pain conditions (Kang et al., 2006; Zhang et al., 2008; Simonetti et al., 2013). Future studies regarding dynamic changes of TRPA1-associated proteins could therefore open the possibility to develop targeted therapeutics for TRPA1-related pain disorders.

\section{References}

Akopian AN, Ruparel NB, Jeske NA, Hargreaves KM (2007) Transient receptor potential TRPAl channel desensitization in sensory neurons is agonist dependent and regulated by TRPV1-directed internalization. J Physiol 583:175-193. CrossRef Medline

Anggono V, Huganir RL (2012) Regulation of AMPA receptor trafficking and synaptic plasticity. Curr Opin Neurobiol 22:461-469. CrossRef Medline

Bandell M, Story GM, Hwang SW, Viswanath V, Eid SR, Petrus MJ, Earley TJ, Patapoutian A (2004) Noxious cold ion channel TRPA1 is activated by pungent compounds and bradykinin. Neuron 41:849-857. CrossRef Medline

Bautista DM, Movahed P, Hinman A, Axelsson HE, Sterner O, Högestätt ED, Julius D, Jordt SE, Zygmunt PM (2005) Pungent products from garlic activate the sensory ion channel TRPA1. Proc Natl Acad Sci U S A 102: 12248-12252. CrossRef Medline

Bautista DM, Jordt SE, Nikai T, Tsuruda PR, Read AJ, Poblete J, Yamoah EN, Basbaum AI, Julius D (2006) TRPA1 mediates the inflammatory actions of environmental irritants and proalgesic agents. Cell 124:1269-1282. CrossRef Medline

Caterina MJ, Leffler A, Malmberg AB, Martin WJ, Trafton J, Petersen-Zeitz KR, Koltzenburg M, Basbaum AI, Julius D (2000) Impaired nociception and pain sensation in mice lacking the capsaicin receptor. Science 288: 306-313. CrossRef Medline

Chen Y, Yang C, Wang ZJ (2011) Proteinase-activated receptor 2 sensitizes transient receptor potential vanilloid 1 , transient receptor potential vanilloid 4, and transient receptor potential ankyrin 1 in paclitaxel-induced neuropathic pain. Neuroscience 193:440-451. CrossRef Medline

Coste B, Mathur J, Schmidt M, Earley TJ, Ranade S, Petrus MJ, Dubin AE, Patapoutian A (2010) Piezol and Piezo2 are essential components of distinct mechanically activated cation channels. Science 330:55-60. CrossRef Medline

da Costa DS, Meotti FC, Andrade EL, Leal PC, Motta EM, Calixto JB (2010) The involvement of the transient receptor potential A1 (TRPA1) in the maintenance of mechanical and cold hyperalgesia in persistent inflammation. Pain 148:431-437. CrossRef Medline

Dai Y, Wang S, Tominaga M, Yamamoto S, Fukuoka T, Higashi T, Kobayashi K, Obata K, Yamanaka H, Noguchi K (2007) Sensitization of TRPAl by PAR2 contributes to the sensation of inflammatory pain. J Clin Invest 117:1979-1987. CrossRef Medline

Dathe C, Daigeler AL, Seifert W, Jankowski V, Mrowka R, Kalis R, Wanker E, Mutig K, Bachmann S, Paliege A (2014) Annexin A2 mediates apical trafficking of renal $\mathrm{Na}+-\mathrm{K}+-2 \mathrm{Cl}$ - cotransporter. J Biol Chem 289:99839997. CrossRef Medline

del Camino D, Murphy S, Heiry M, Barrett LB, Earley TJ, Cook CA, Petrus MJ, Zhao M, D'Amours M, Deering N, Brenner GJ, Costigan M, Hayward NJ, Chong JA, Fanger CM, Woolf CJ, Patapoutian A, Moran MM (2010) TRPA1 contributes to cold hypersensitivity. J Neurosci 30:15165-15174. CrossRef Medline

Diogenes A, Akopian AN, Hargreaves KM (2007) NGF up-regulates TRPA1: implications for orofacial pain. J Dent Res 86:550-555. CrossRef Medline

Donier E, Rugiero F, Okuse K, Wood JN (2005) Annexin II light chain p11 promotes functional expression of acid-sensing ion channel ASICla. J Biol Chem 280:38666-38672. CrossRef Medline

Foulkes T, Nassar MA, Lane T, Matthews EA, Baker MD, Gerke V, Okuse K, Dickenson AH, Wood JN (2006) Deletion of annexin 2 light chain p11 in nociceptors causes deficits in somatosensory coding and pain behavior. J Neurosci 26:10499-10507. CrossRef Medline

Gerke V, Creutz CE, Moss SE (2005) Annexins: linking Ca2+ signalling to membrane dynamics. Nat Rev Mol Cell Biol 6:449-461. CrossRef Medline

Gómez-Varela D, Schmidt M, Schoellerman J, Peters EC, Berg DK (2012) PMCA2 via PSD-95 controls calcium signaling by alpha7-containing nicotinic acetylcholine receptors on aspiny interneurons. J Neurosci 32: 6894-6905. CrossRef Medline

He KL, Deora AB, Xiong H, Ling Q, Weksler BB, Niesvizky R, Hajjar KA (2008) Endothelial cell annexin A2 regulates polyubiquitination and degradation of its binding partner S100A10/p11. J Biol Chem 283:19192_ 19200. CrossRef Medline

Huang D, Li S, Dhaka A, Story GM, Cao YQ (2012) Expression of the transient receptor potential channels TRPV1, TRPA1 and TRPM8 in mouse trigeminal primary afferent neurons innervating the dura. Mol Pain 8:66. CrossRef Medline

Hucho T, Levine JD (2007) Signaling pathways in sensitization: toward a nociceptor cell biology. Neuron 55:365-376. CrossRef Medline

Jordt SE, Bautista DM, Chuang HH, McKemy DD, Zygmunt PM, HögestättED, Meng ID, Julius D (2004) Mustard oils and cannabinoids excite 
sensory nerve fibres through the TRP channel ANKTM1. Nature 427: 260-265. CrossRef Medline

Kang SK, So HH, Moon YS, Kim CH (2006) Proteomic analysis of injured spinal cord tissue proteins using 2-DE and MALDI-TOF MS. Proteomics 6:2797-2812. CrossRef Medline

Keller A, Nesvizhskii AI, Kolker E, Aebersold R (2002) Empirical statistical model to estimate the accuracy of peptide identifications made by MS/MS and database search. Anal Chem 74:5383-5392. CrossRef Medline

Kwan KY, Allchorne AJ, Vollrath MA, Christensen AP, Zhang DS, Woolf CJ, Corey DP (2006) TRPA1 contributes to cold, mechanical, and chemical nociception but is not essential for hair-cell transduction. Neuron 50: 277-289. CrossRef Medline

Ling Q, Jacovina AT, Deora A, Febbraio M, Simantov R, Silverstein RL, Hempstead B, Mark WH, Hajjar KA (2004) Annexin II regulates fibrin homeostasis and neoangiogenesis in vivo. J Clin Invest 113:38-48. CrossRef Medline

Liu XJ, Gingrich JR, Vargas-Caballero M, Dong YN, Sengar A, Beggs S, Wang SH, Ding HK, Frankland PW, Salter MW (2008) Treatment of inflammatory and neuropathic pain by uncoupling Src from the NMDA receptor complex. Nat Med 14:1325-1332. CrossRef Medline

Macpherson LJ, Dubin AE, Evans MJ, Marr F, Schultz PG, Cravatt BF, Patapoutian A (2007) Noxious compounds activate TRPA1 ion channels through covalent modification of cysteines. Nature 445:541-545. CrossRef Medline

Malsch P, Andratsch M, Vogl C, Link AS, Alzheimer C, Brierley SM, Hughes PA, Kress M (2014) Deletion of interleukin-6 signal transducer gp130 in small sensory neurons attenuates mechanonociception and downregulates TRPA1 expression. J Neurosci 34:9845-9856. CrossRef Medline

Mayran N, Parton RG, Gruenberg J (2003) Annexin II regulates multivesicular endosome biogenesis in the degradation pathway of animal cells. EMBO J 22:3242-3253. CrossRef Medline

Meseguer V, Alpizar YA, Luis E, Tajada S, Denlinger B, Fajardo O, Manenschijn JA, Fernández-Pena C, Talavera A, Kichko T, Navia B, Sánchez A, Señarís R, Reeh P, Pérez-García MT, López-López JR, Voets T, Belmonte C, Talavera K, Viana F (2014) TRPAl channels mediate acute neurogenic inflammation and pain produced by bacterial endotoxins. Nat Commun 5:3125. CrossRef Medline

Minett MS, Quick K, Wood JN (2011) Behavioral measures of pain thresholds. In: Current protocols in mouse biology. New York: Wiley.

Morel E, Gruenberg J (2009) Annexin A2 binding to endosomes and functions in endosomal transport are regulated by tyrosine 23 phosphorylation. J Biol Chem 284:1604-1611. CrossRef Medline

Naciff JM, Kaetzel MA, Behbehani MM, Dedman JR (1996) Differential expression of annexins I-VI in the rat dorsal root ganglia and spinal cord. J Comp Neurol 368:356-370. CrossRef Medline

Nagata K, Duggan A, Kumar G, García-Añoveros J (2005) Nociceptor and hair cell transducer properties of TRPA1, a channel for pain and hearing. J Neurosci 25:4052-4061. CrossRef Medline

Ning L, Wang C, Ding X, Zhang Y, Wang X, Yue S (2012) Functional interaction of TRPV4 channel protein with annexin A2 in DRG. Neurol Res 34:685-693. CrossRef Medline

Obata K, Katsura H, Mizushima T, Yamanaka H, Kobayashi K, Dai Y, Fukuoka T, Tokunaga A, Tominaga M, Noguchi K (2005) TRPA1 induced in sensory neurons contributes to cold hyperalgesia after inflammation and nerve injury. J Clin Invest 115:2393-2401. CrossRef Medline

Okuse K, Malik-Hall M, Baker MD, Poon WY, Kong H, Chao MV, Wood JN (2002) Annexin II light chain regulates sensory neuron-specific sodium channel expression. Nature 417:653-656. CrossRef Medline

Park CK, Xu ZZ, Berta T, Han Q, Chen G, Liu XJ, Ji RR (2014) Extracellular microRNAs activate nociceptor neurons to elicit pain via TLR7 and TRPA1. Neuron 82:47-54. CrossRef Medline

Patapoutian A, Tate S, Woolf CJ (2009) Transient receptor potential channels: targeting pain at the source. Nat Rev Drug Discov 8:55-68. CrossRef Medline

Petrus M, Peier AM, Bandell M, Hwang SW, Huynh T, Olney N, Jegla T, Patapoutian A (2007) A role of TRPA1 in mechanical hyperalgesia is revealed by pharmacological inhibition. Mol Pain 3:40. CrossRef Medline

Rankin CR, Hilgarth RS, Leoni G, Kwon M, Den Beste KA, Parkos CA, Nusrat A (2013) Annexin A2 regulates betal integrin internalization and intes- tinal epithelial cell migration. J Biol Chem 288:15229-15239. CrossRef Medline

Rescher U, Gerke V (2004) Annexins-unique membrane binding proteins with diverse functions. J Cell Sci 117:2631-2639. CrossRef Medline

Ruparel NB, Patwardhan AM, Akopian AN, Hargreaves KM (2008) Homologous and heterologous desensitization of capsaicin and mustard oil responses utilize different cellular pathways in nociceptors. Pain 135:271279. CrossRef Medline

Schmidt M, Dubin AE, Petrus MJ, Earley TJ, Patapoutian A (2009) Nociceptive signals induce trafficking of TRPA1 to the plasma membrane. Neuron 64:498-509. CrossRef Medline

Schwenk J, Harmel N, Brechet A, Zolles G, Berkefeld H, Müller CS, Bildl W, Baehrens D, Huber B, Kulik A, Klöcker N, Schulte U, Fakler B (2012) High-resolution proteomics unravel architecture and molecular diversity of native AMPA receptor complexes. Neuron 74:621-633. CrossRef Medline

Simonetti M, Hagenston AM, Vardeh D, Freitag HE, Mauceri D, Lu J, Satagopam VP, Schneider R, Costigan M, Bading H, Kuner R (2013) Nuclear calcium signaling in spinal neurons drives a genomic program required for persistent inflammatory pain. Neuron 77:43-57. CrossRef Medline

Staruschenko A, Jeske NA, Akopian AN (2010) Contribution of TRPV1TRPA1 interaction to the single-channel properties of the TRPA1 channel. J Biol Chem 285:15167-15177. CrossRef Medline

Story GM, Peier AM, Reeve AJ, Eid SR, Mosbacher J, Hricik TR, Earley TJ, Hergarden AC, Andersson DA, Hwang SW, McIntyre P, Jegla T, Bevan S, Patapoutian A (2003) ANKTM1, a TRP-like channel expressed in nociceptive neurons, is activated by cold temperatures. Cell 112:819-829. CrossRef Medline

Svenningsson P, Chergui K, Rachleff I, Flajolet M, Zhang X, El Yacoubi M, Vaugeois JM, Nomikos GG, Greengard P (2006) Alterations in 5-HT1B receptor function by p11 in depression-like states. Science 311:77-80. CrossRef Medline

Takahashi N, Kuwaki T, Kiyonaka S, Numata T, Kozai D, Mizuno Y, Yamamoto S, Naito S, Knevels E, Carmeliet P, Oga T, Kaneko S, Suga S, Nokami T, Yoshida J, Mori Y (2011) TRPAl underlies a sensing mechanism for O2. Nat Chem Biol 7:701-711. CrossRef Medline

Tamma G, Procino G, Mola MG, Svelto M, Valenti G (2008) Functional involvement of Annexin-2 in cAMP induced AQP2 trafficking. Pflugers Arch 456:729-736. CrossRef Medline

Tappe A, Klugmann M, Luo C, Hirlinger D, Agarwal N, Benrath J, Ehrengruber MU, During MJ, Kuner R (2006) Synaptic scaffolding protein Homerla protects against chronic inflammatory pain. Nat Med 12:677681. CrossRef Medline

van de Graaf SF, Hoenderop JG, Gkika D, Lamers D, Prenen J, Rescher U, Gerke V, Staub O, Nilius B, Bindels RJ (2003) Functional expression of the epithelial $\mathrm{Ca}(2+)$ channels (TRPV5 and TRPV6) requires association of the S100A10-annexin 2 complex. EMBO J 22:1478-1487. CrossRef Medline

Vandewauw I, Owsianik G, Voets T (2013) Systematic and quantitative mRNA expression analysis of TRP channel genes at the single trigeminal and dorsal root ganglion level in mouse. BMC Neurosci 14:21. CrossRef Medline

Wang S, Dai Y, Fukuoka T, Yamanaka H, Kobayashi K, Obata K, Cui X, Tominaga M, Noguchi K (2008) Phospholipase C and protein kinase A mediate bradykinin sensitization of TRPA1: a molecular mechanism of inflammatory pain. Brain 131:1241-1251. CrossRef Medline

Wang X, Zhang J, Eberhart D, Urban R, Meda K, Solorzano C, Yamanaka H, Rice D, Basbaum AI (2013) Excitatory superficial dorsal horn interneurons are functionally heterogeneous and required for the full behavioral expression of pain and itch. Neuron 78:312-324. CrossRef Medline

Zhang Y, Wang YH, Zhang XH, Ge HY, Arendt-Nielsen L, Shao JM, Yue SW (2008) Proteomic analysis of differential proteins related to the neuropathic pain and neuroprotection in the dorsal root ganglion following its chronic compression in rats. Exp Brain Res 189:199-209. CrossRef Medline

Zhou Y, Suzuki Y, Uchida K, Tominaga M (2013) Identification of a splice variant of mouse TRPA1 that regulates TRPA1 activity. Nat Commun 4:2399. CrossRef Medline 